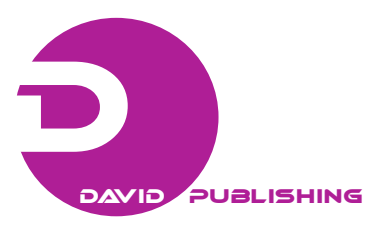

\title{
Using Condensed Water of Air Conditioners for Toilet Flushing: A Case Study in Brazil
}

\author{
Celso Silva Bastos and João Luiz Calmon \\ Postgraduate Program in Civil Engineering, Technology Center, Federal University of Espírito Santo, Vitória 29000-000, Brazil
}

\begin{abstract}
Within the concept of sustainable construction, with sensible and conscious use of finite natural resources, every effort to save and reuse raw-materials is considered an important step to be adopted in buildings, from project, implantation and construction to operation and maintenance throughout their lifecycle. This study aims at showing the application of a system that reuses condensed water drained from air-conditioner evaporators (which are usually disposed of), and a plan to use this water for toilet flushing, reducing consumption of treated water bought from water companies. The authors verified that each air-conditioner specified in the project of a commercial building —used as reference here-produces $4.8 \mathrm{~L}$ of water per hour of operation. This result in a daily accumulated volume of 4,290 L, which represents a significant part of the amount needed to supply all the toilets in the building. A water capture system located at a strategic intermediate floor would be able to store this water and pump it into a special reservoir on the roof of the building, to be distributed into toilet flush pipes. By applying this technology, the authors seek to considerably reduce the expected treated water consumption and consequently decrease water bill costs.
\end{abstract}

Key words: Water reuse, air-conditioner, toilet flush.

\section{Introduction}

A growing number of countries are now experiencing increasing water stresses because of a higher demand for usable water and a failure to protect available resources from pollution. Water is a precious and scarce commodity that should be properly managed and effectively utilized [1].

Water resource management is one of the greatest challenges of the present century. As populations climb, per-capita use increases, and current water supplies grow shorter, water resources are becoming more critical globally. Most urban areas face difficult choices and expensive solutions to meet existing and future demand [2].

Of all the water available on Earth, 97.6\% is concentrated in the oceans. Fresh water corresponds to the remaining $2.4 \%$. Of these $2.4 \%$, only $0.31 \%$ is not concentrated on the Poles in the form of ice. Of all the

Corresponding author: Celso Silva Bastos, M.Sc., research fields: construction technology with low environmental impact, higher performance and lower power consumption, quality of the building environment and sustainability. E-mail: celsobastos10@gmail.com. water on Earth's surface, less than $0.02 \%$ is available in rivers and lakes as fresh water ready for consumption. Water distribution in the world is very unequal, most part of the planet located in are areas where water is scarce. These countries are the ones responsible for developing technologies that allow them to capture, store and preserve water and water sources by monitoring consumption and quality so as to avoid contamination by pollutants. The solutions currently employed for several activities are desalinization, wastewater treatment and rainwater capture. Graywater and rainwater reuse is the object of many studies and applications aiming at reducing consumption and the water bills. The poor standardization of these solutions is many times responsible for a reckless use of water, which may put the population's health at risk.

One of the main principles of globally applicable sustainable development described in the Declaration of Rio, known as Agenda 21, issued during Rio-92, maintains that due to increase in consumption and its paucity in some areas, water is now considered as an 
asset. The document describes "The growing water scarcity: a key-question that is related to warmer climates, as well as increase in population and pollution” [3].

In the civil construction industry in special, during the operation phase of buildings, water is responsible for a significant portion of impact on the environment. Water losses in building systems due to poor quality of materials, components and procedures related to inappropriate water use result in higher volumes of consumption and input needed for treating water and sewage, besides the environmental degradation resulting from production of these inputs [4].

Today the concern about sustainable construction is evident, and several methodologies have been developed in order to assess environmental performance of buildings, among them is LEED (leadership in energy and environmental design), CASBEE (comprehensive assessment system for building environment efficiency), and BREEAM (building establishment environmental assessment method), which are used as tools for projects and works aiming at decreasing environmental impact caused by constructions, reducing material consumption, increasing performance and durability so as to prolong service life, and offering lower operational and maintenance costs [5]. Among these methodologies, water consumption is always considered to significantly influence the expected results. LEED aims at reducing 50\% of water consumption by reclaiming water.

The topic water reuse boosted several studies and research, mainly in other countries with higher scarcity of this element. In most cases, water reclamation takes place in industries [6] and agriculture. It receives a different treatment depending on its end. The civil construction market has already signed its participation in this segment, showing the advantages of building in a way to reduce consumption and engage in green industries [7].

Projects aiming at effective water management, treatment and reuse have been implanted in Mediterranean and Middle East countries, seeking to increase water supply security by raising public awareness and implementing innovative solutions to each reality [8].

Graywater has been used along with rainwater as alternative resources, but paucity of data about these combined sources makes the application of these systems difficult. Studies on new treatment options have been proposed through special filters [9].

The scale, water quality, safety criteria and water reuse management need to be studied and improved. Water reuse has been carried out in large scale in countries such as China, where several treatment stations are operational and present increasing results in terms of water reuse percentage to improve environmental sustainability [10].

Civil construction has introduced water reuse into buildings for several purposes, reusing graywater and rain water in most cases. An effective result of graywater reuse after chemical and physical treatment is obtained in toilet flushing in vertical buildings [11].

In cities where there is a favorable history of precipitation, studies proposing techniques for building water reuse systems have been developed, and some of them corroborate the efficiency by reducing water demand by $35 \%$, such as in schools in the district of Taipei [12].

This water has relatively good quality and after a few treatment stages, it could be used as drinking and non-drinking water, meeting several demands in the operation of a building [13].

Few studies with other options besides those already mentioned were found as an alternative to the issue of water use in constructions. This study aims at contributing to reduction in drinking water consumption and showing the feasibility of reusing water drained from air conditioning evaporator condensation for toilet flushing in a commercial or institutional building, thus providing large water savings. 


\section{Objective and Justification}

This study aims at showing the technical feasibility of reusing the waste water from air conditioning system condensation for toilet flushing. As case-study, the authors were based on the construction site of a building that will work as a higher education institution. This type business in the city of Vitória, ES, Brazil, where it is located, is considered a commercial building because there is no particular regulation for higher education institutions. Only childcare and elementary school buildings must comply with specific construction standards for education [14].

The idea of applying this technological innovation started when complementary projects were compatibilized with the architectural project, and when the authors verified the amount of water produced by evaporators, the drainage necessary for each air conditioning device, and the non-use of this water in other parts of the building. Few references of studies using the same model have been found in the relevant literature, which offers new opportunities and justifies this study in a time in which there are several water supply problems: growing consumption and high rate of drinking water waste.

In face of this problem, the authors expect to contribute with a proposal that may become reference and motivation to future studies based on the results predicted. This initiative will be an important principle for constructions aiming at reducing environmental impacts and increasing performance. This procedure can be improved in a near future and receive incentives for voluntary and regulated applications.

\section{Case Study in Brazil}

Structure of the systems is as following, the undertaking on which this study was based is a building construction in the city of Vitória, ES, Brazil made up of 12 floors: five garage levels for cars and motorcycles and seven levels comprising classrooms, laboratories, library, administration offices, living areas, cafeteria and other support and service areas distributed according to the institution's needs.

All the projects were subject to interference and adaptations so that the system proposed in this study could be implemented. The needs of concerning the intended alteration were verified in architectural design because the early project did not comprise these principles.

The project opted for 4-way cassette type evaporating units with variable dimensioning installed into the drop ceiling of each room and dimensioned to meet thermal comfort demands in compliance with manufacturer's specification, resulting in better equipment performance and indoor air quality. A new drop ceiling plan was designed to receive the evaporators and not interfere with the lighting and other installations.

A place for the installations of the proposed system was reserved on one of the garage floors, without affecting the parking of vehicles. The bipartite upper reservoir, located on the roof, now has three parts, one exclusively for storing condensation water-which cannot be stored with treated water. This reservoir will be interconnected to other reservoirs so that toilet water supply is not compromised if the demand is higher than that expected. This study does not comprise a laboratorial analysis of the water captured from evaporators because it will be separated from treated water and will be used exclusively for toilet flushing. There will be no other consumption purposes.

The hydro-sanitary project defined the route and dimension of evaporator piping: from air conditioning device output, through the equipment that will pump it to the upper water reservoir, and back to toilet flushing of restrooms above the garage floors.

The city of Vitória in the state of Espírito Santo is located in Southeastern Brazil, at 20 $0^{\circ} 19^{\prime} 09$ "South latitude and $40^{\circ} 20^{\prime} 50^{\prime \prime}$ West longitude on an island, offering favorable climatic conditions, rainy tropical 
climate, no cold season, dry season during winter and average temperature of $23.5^{\circ} \mathrm{C}$. These characteristics favor the use of clean, renewable and sustainable solar energy. This was the option chosen to feed the pumps that will supply the upper reservoir and make the system self-sufficient and independent. Photovoltaic solar energy generators can ensure the required energy to operate the solar module without using batteries, even during overcast days. In order to ensure energy supply in case of any problem in the solar system, it will be connected to power supplied by the electric company.

This study focuses on the feasibility of reusing waste water from air conditioning evaporator condensation. However, it is important to highlight that the building project foresees the use of rain water washing the lower floors and watering the garden. The city has annual precipitation of 1,292.2 $\mathrm{mm}$. The surplus water from both air conditioning system and rain capture will be used in general cleaning services.

\section{System Dimensioning (Practical Application)}

Part of the air breathed is composed of diluted water vapor. For vapor to return to liquid state, surface temperature has to be below dew point temperature, which is the temperature at which the water vapor in ambient air turns into liquid in the form of small drops (condensation).

In practical terms, in the conditions of city of Vitória, this temperature is below $17^{\circ} \mathrm{C}$, even in air conditioned environments. In the air conditioning system, there are two main elements: an inside and an outside unit. The temperature of the coiled tube through which the air in the inside unit passes is below $12^{\circ} \mathrm{C}$, making part of the air vapor return to liquid state. Taking into account that to turn $1 \mathrm{~kg}$ of humid air into water, latent heat of vaporization is 538 $\mathrm{kcal} / \mathrm{kg}$ to alter its physical state from vapor to liquid. Only $30 \%$ of the air passing through the coiled tube gets in contact with tube surface. Usually, air conditioning device capacity is from $30 \%$ to $70 \%$ of sensible heat removal, and $30 \%$ to $70 \%$ of latent heat removal (Fig. 1).

Table 1 shows the amount of water produced per floor by draining the 137 evaporators of different refrigeration capacities in BTU (British thermal unit), that are distributed in the building, results in an amount of 4,298.1 Litres per working day. This water

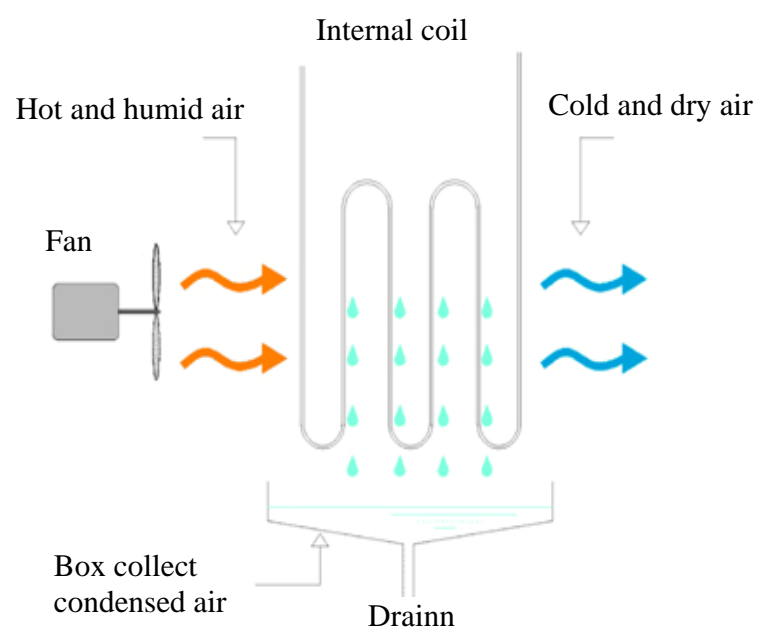

Fig. 1 Water condensation system in the coiled tube.

Table 1 Capacities and capacity of water removal from air of used equipment.

\begin{tabular}{lllllc}
\hline Floor & $\begin{array}{l}\text { Total capacity } \\
\text { (btu/h) }\end{array}$ & $\begin{array}{l}\text { Capacity of latent heat } \\
\text { removal (btu/h) }\end{array}$ & $\begin{array}{l}\text { Operation day } \\
\text { (hours) }\end{array}$ & $\begin{array}{l}\text { Cond. } \\
\text { (Water) (L/h) }\end{array}$ & $\begin{array}{l}\text { Cond. } \\
\text { (Water) (L/day) }\end{array}$ \\
\hline Floor 05 & 646,900 & 419,045 & 12 & 58.9 & 706.8 \\
Floor 06 & 673,600 & 437,840 & 9 & 61.5 & 553.5 \\
Floor 07 & 735,600 & 478,140 & 9 & 67.2 & 604.8 \\
Floor 08 & 735,600 & 478,140 & 9 & 67.2 & 604.8 \\
Floor 09 & 516,100 & 335,465 & 12 & 47.1 & 565.2 \\
Floor 09 (Auditorium) & 229,200 & 148,980 & 6 & 20.9 & 125.4 \\
Floor 10 & 735,600 & 478,140 & 9 & 67.2 & 604.8 \\
Floor 11 & 648,400 & 421,460 & 9 & 59.2 & 532.8 \\
Total/Day & & & & $4,298.1$ \\
\hline
\end{tabular}


will be captured and stored in a reservoir destined for this purpose, pumped to the upper reservoir, and then used for toilet flushing. Total generation of water produced by the evaporators will be 4,298.1 L.

The conventional hydro-sanitary project considered installing a $5 \mathrm{CV}$ elevation pump with output rate of $16.60 \mathrm{~m}^{3} / \mathrm{h}$ at manometric height of $50 \mathrm{~m} \mathrm{H}_{2} \mathrm{O}$. Upper reservoir capacity will be $8.86 \mathrm{~m}^{2} \times 0.63 \mathrm{~m}=5.53 \mathrm{~m}^{3}$.

Elevation pump will be activated when water level (NA) lowers $0.63 \mathrm{~m}$, if solar energy system is not operating at that moment because of maintenance of malfunctioning. If the hydraulic pump of conventional system pumps $16.60 \mathrm{~m}^{3} / \mathrm{h}$, it will pump 4,298.1 L in 15 minutes.

Considering a population of 820 people -720 students, 60 professors, and 40 employees-and estimating $100 \%$ of daily consumption per person, toilet flush consumption in liters will be 9 L. Daily consumption is calculated for use by $75 \%$ of the population. If daily consumption in $100 \%$ of use represents $820 \times 9=7,380 \mathrm{~L}$, estimate daily consumption with $75 \%$ of population will be $5,530 \mathrm{~L}$. Reservoir of water from air conditioning units will have a 7,500-litre capacity.

The conclusion of results shown in Table 2 shows that the system reaches a significant water saving factor, surpassing the indices foreseen in existing methodologies for a more sustainable construction.

As parallel alternative to conventional system and maintaining the concept of clean and renewable energy, installation of solar pumping consists in transforming continuous electric energy generated by solar modules into alternate current as effectively as possible. The system works independent of fluctuation of solar radiation levels, that is, there will always be water pumping at any time of the day, regardless of weather conditions, as long as modules supply current of at least 0.1 ampere. One piece of equipment will work with a control that will be responsible for converting the energy supplied by the solar modules into constant and spaced energy pulses according to the solar radiation level. The system does not require batteries, which reduces maintenance needs.

Based on project data, piping manometric height is $42 \mathrm{~m}$. Since daily flow rate is $4,298.1 \mathrm{~L}$, the system will require three water pumps brand Shurflo, model number 9300, submersed in the condensed water accumulation tank, with six solar modules attached to it, two for each pump, installed on the building roof, in compliance with manufacturer's specifications. Each solar modules has an output of $115 \mathrm{Wp}$ (watts peak).

For foreseen pumping flow rate of $375 \mathrm{~L} / \mathrm{h}$ and 3 pumps with continuous and simultaneous operation, total flow will be $1.125 \mathrm{~L} / \mathrm{h}$. Taking into account that captured volume to be pumped is 4,298.1 L, total time to take this water to upper reservoir will be about $4 \mathrm{~h}$ and the distance is $22 \mathrm{~m}$. This represents a relative disadvantage compared to the conventional system, which takes $15 \mathrm{~m}$, but there will be no use of electricity from the power company and the system will close its self-sufficient loop. Fig. 2 represents the operation cycle of the system proposed in this study, from location of equipment until its operation in the building.

\section{Conclusions}

The present study shows that it is feasible to use water drained from air conditioning systems, mainly in commercial building with several units installed. Nowadays, all this water is wasted, not used even for watering gardens or washing sidewalks. The water demand calculated for use in toilet flushing is close to

Table 2 Final results.

\begin{tabular}{llll}
\hline Daily population (people) & Daily consumption for toilet flush (L) & $\begin{array}{l}\text { Amount of drained and } \\
\text { stored water (L) }\end{array}$ & $\begin{array}{l}\text { Economy expected with water } \\
\text { consumption (\%) }\end{array}$ \\
\hline 820 & 5.530 & $4,298.1$ & 77.72 \\
\hline
\end{tabular}




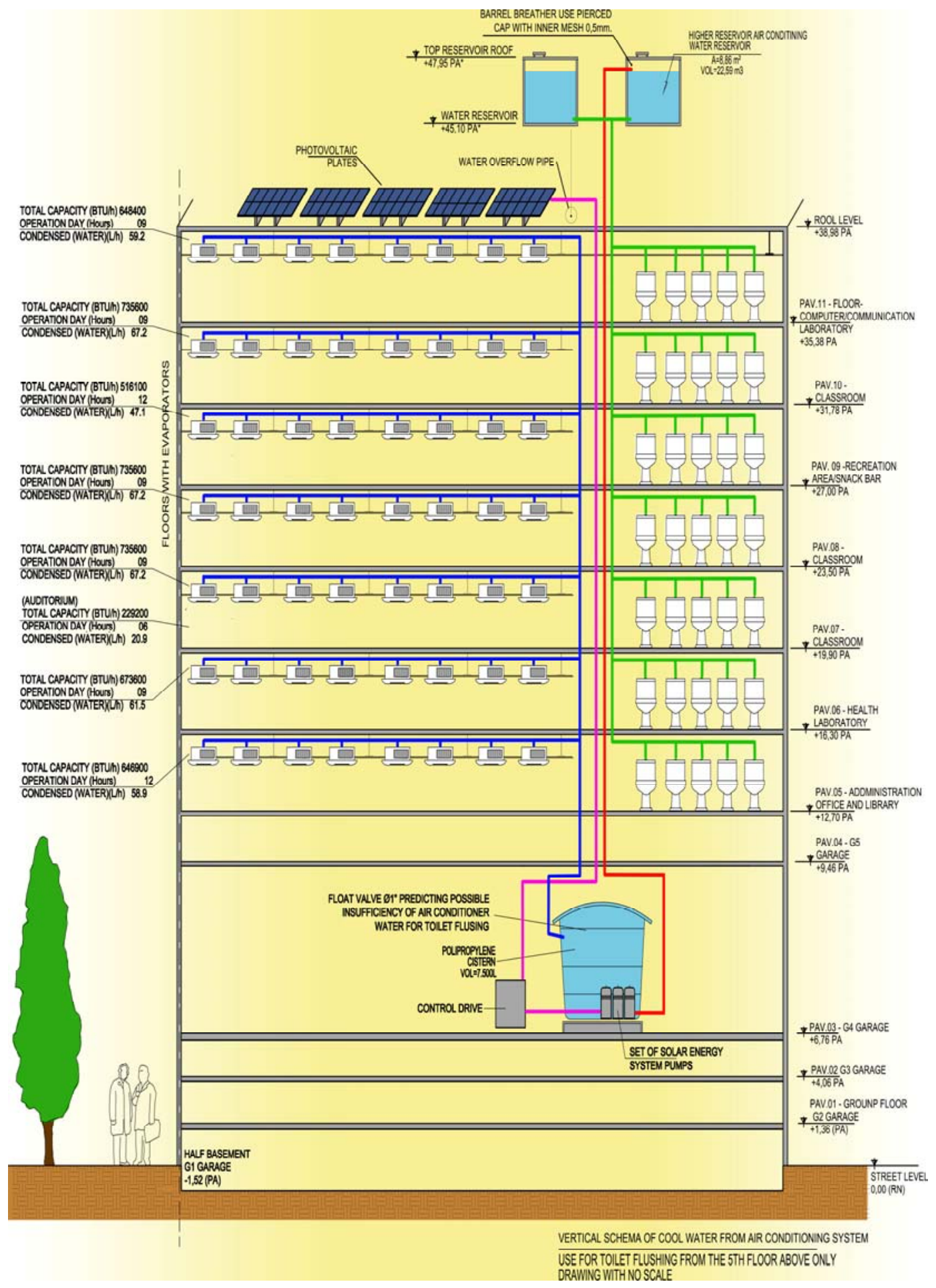

Fig. 2 System general schema.

the amount of water captured by the drainage system of evaporators, which represents $77.72 \%$ of calculated consumption.

This means a significant economical result in building operations and a great advance towards environmental issues concerning drinking water reuse.

Compared to rain water reuse, this system presents advantages because the building will be operational producing condensed water every day during business hours, whereas rain water is periodical, with no 
constant operation, which can damage piping and pumps due to drying or idleness.

Therefore, the authors can conclude that if there is enough flow to reuse water which is indirectly generated through daily regular operation of a building and if there is demand for consuming this water, the importance of using and incentivizing this system is undeniable, especially in a moment when every contribution to reducing environmental impacts caused by construction have become extremely important in the global scenario. Every professional and business owner linked to civil construction should show initiative by practicing, setting examples, and mainly developing and improving new techniques to soften the environmental impact caused by constructions.

\section{References}

[1] N. Spulber, A. Sabbaghi, Economics of Water Resources: From Regulation to Privatization, 2nd ed., Water Resource Management, Kluwer Academic Publishers, Boston, 1998, p. 342.

[2] J. Donofrio, Y. Kuhn, K. Mcwalter, M. Winsor, Water-sensitive urban design: An emerging model in sustainable design and comprehensive water-cycle management, Environmental Practice 11 (3) (2009) 179-189.

[3] S. Roaf, F. Nicol, D. Crichton, Cities and Building Adaptations to Climate Change, Porto Alegre, Brookman, 2009. (in Portuguese)

[4] L.H. Oliveira, M. Ilha, R.P.A. Reis, State of Art Research: Water, Document 2.1 Technologies for A More Sustainable Housing Development Project, Finep Project 2386/04, São Paulo, 2007, p. 107. (in Portuguese)

[5] L.S. Araújo, Environment Performance in Municipal Health Buildings in the City Vitória: Test Project and
Recommendations for LEED-NC 2.2 Certification, UFES (Federal University of Espírito Santo), Vitória, 2009, p. 249. (in Portuguese)

[6] I. Hespanhol, J.C. Mierzwa, L. Rodrigues, M. Silva, Guidelines for Water Conservation and Reuse for Industry Application, International Reference Center on Water Reuse, Fiesp/Ciesp, São Paulo, 2003, p. 92. (in Portuguese)

[7] I. Hespanhol, O.M. Gonçalves, Water Conservation and Reuse of Building, International Reference Center on Water Reuse, Fiesp/Ciesp, São Paulo, p. 152, 2005. (in Portuguese)

[8] L. Petta, A. Kramer, I.A. Baz, The EMWalter project-promoting efficient waste water management and reuse in Mediterranean countries, Desalination 215 (1-3) (2007) 56-63.

[9] R.H. Kim, S. Lee, J. Jeong, J.H. Lee, Y.K. Kim, Reuse of greywater and rainwater using fiber filter media and metal membrane, Original Research Article Desalination 202 (1-3) (2007) 326-332.

[10] Y. Zhou, J. Li, C. Chang, S. Wei, Y. Ni, Y. Zhang, Status and development municipal wastewater reuse in China, in: International Symposium on Water Resource and Environmental Protection, China, 2011, pp. 3183-3186.

[11] E. Friedler, R. Kovalio, N.I. Galil, On-site greywater treatment and reuse in multi-storey buildings, Water Science \& Tecnology 51 (10) (2005) 187-194.

[12] T.C. Wung, S.H. Lin, S.M. Huang, Rainwater reuse supply and demand response in urban elementary school of different districts in Taipei, Original Research Article Resources, Conservation and Recycling 46 (2) (2006) 149-167.

[13] H. Liu, L. Xu, Y. Zhao, J. Bao, Research and discussion on the purification technology of roof rain water for household in islands in China, in: International Conference on Remote Sensing, Environment and Transportation Engineering, China, 2011, pp. 4302-4305.

[14] Law n 4424, Art. 113, Section III of April 10, 1997, Sanitary Code of the City of Vitória, Vitória City, Espírito Santo-Brazil, Apr. 15, 1997. 